\title{
APOKRIFNI POPIS PLEMIĆKIH RODOVA BOSANSKOGA KRALJEVSTVA
}

Stjepan ĆOSIĆ

Filozofski fakultet Split

Odsjek za povijest

Sinjska 2

HR- 21000 Split

E-pošta: stjepan.cosic@ffst.hr

\author{
UDK: 929.7(497.6)(091) \\ Izvorni znanstveni rad \\ Primljeno: 16. studenoga 2016 \\ Prihvaćeno: 5. travnja 2017
}

\section{Sažetak}

Dulje od dva stoljeća u historiografiji i publicistici prisutne su veoma slične verzije popisâ plemićkih rodova Bosne i Huma iz predosmanskoga doba. Jedna inačica objavljena je i u dvjema poznatim zbirkama izvora za povijest $\mathrm{BiH}$ čime je popis dobio na znanstvenoj vjerodostojnosti. Međutim, podatci o podrijetlu i nastanku popisa ne potvrđuju njegovu autentičnost. Popis je jedan od apokrifnih dokumenata koji je nastao u sklopu tzv. ilirske heraldike. Riječ je o kompleksnom ideološkom fenomenu koji se razvijao na tragu protuosmanske politike 17. i 18. stoljeća, s ciljem da se legitimiraju feudalni interesi određenih rodovskih krugova, kao i "povrat" njihovih privilegija i posjeda, prvenstveno na području $\mathrm{BiH}$. $\mathrm{Na}$ tu tradiciju pozivali su se i neki rodovi Makarskoga primorja, a u makarskom se franjevačkom samostanu čuva i najstariji prijepis popisa kojega je, prema jednoj vijesti, 1724. iz Fojnice donio fra Marijan Lekušić. Popis se sastoji od donekle modificiranog i proširenog slijeda rodova iz Fojničkoga grbovnika koji je nastao nakon 1675 . godine. Znatnom broju rodova u popisu je dodano i mjesto podrijetla i to na temelju spoznaja o njihovu zavičaju početkom 18. stoljeća. Nakon ma- 
karske verzije popisa koju su publicirali fra Andrija Kačić Miošić i fra Luka Vladmirović, pojavio se i veoma sličan popis što ga je u franjevački samostan u Budimu iz Bosne donio fra Josip Jakošić. Godine 1789. Martin Juraj Kovačić tiskao je taj popis kao dodatak knjizi Gabrijela Kolinovića. Prema budimskoj inačici popis su kasnije, u svojim zbirkama vrela, objavili Grgur Cevapović i Euzebije Fermendžin. Širenje i nekritičko prihvaćanje apokrifnih podataka iz popisa i drugih izvora ilirske heraldike prouzročilo je brojne pogrješke i zablude u genealoškim i heraldičkim istraživanjima.

Ključne riječi: Popis bosanskoga i humskoga plemstva; Marijan Lekušić; Andrija Kačić Miošić; Luka Vladmirović; Makarska; Fojnica; Budim; ilirska heraldika; Fojnički grbovnik; Korjenić-Neorićev grbovnik; Gabrijel Kolinović Šenkvički; Josip Jakošić; Martin Juraj Kovačić; Grgur Ćevapović; Euzebije Fermendžin.

U drugom izdanju Razgovora ugodnog naroda slovinskoga fra Andrije Kačića Miošića iz 1759. tiskana je "Pisma od Stipana Kristića i njegovi svatova". U njoj je opjevana svadba bosanskoga kralja Stjepana Tomaša i Katarine Kosače ("Kate Hercegovke"), događaj koji se zbio godine 1446. Među svatovima koje kralj poziva, pjesnik niže vlastelu dodajući svakome od njih mjesto ili kraj iz kojega potječe. Dalje u svojoj pismarici Kačić je na više mjesta varirao fabule o plemićima i rodovima koji se spominju u toj pjesmi. Prošireni niz od 167 rodova, od kojih je većini pridodao mjesto podrijetla Kačić donosi i u proznom zapisu u obliku dokumenta pod naslovom: "Slide knezovi i vlastela naroda slovinskoga".' Isti popis vlastele (dalje: Popis), s jednakim naslovom, pretiskao je Kačić i u svojoj Korabljici godine $1760 .^{2}$

U kojoj mjeri je ovaj Popis autentičan te kada je i kako nastao? Gotovo jednak, nešto opširniji niz od 179 bosanskih plemićkih rodova $\mathrm{s}$ podatcima o njihovu podrijetlu, tiskao je tri desetljeća nakon Kači-

1 AndRIJA KaČIĆ MiošIĆ, Razgovor ugodni naroda slovinskoga, Stari pisci hrvatski XXVII., knjiga prva, Tомо Matić (prir.), HAZU, Zagreb, 1942., str. 207-210, 380-389.

2 ANdrija Kačić Miošić, Korabljica, Stari pisci hrvatski XXVII., knjiga druga, Tомо Matić (prir.), HAZU, Zagreb, 1942., str. 290-295. 
ća njegov subrat i prijatelj fra Luka Vladmirović (1718.-1788.). Popis predstavlja prvi dodatak u Vladmirovićevoj knjizi De Regno Bosniae, ejusque interitu, narratio historica etc. iz 1781. koju je objavio u Veneciji pod pseudonimom Prudentius Narentinus. Odjeljak nosi naslov: "Dodatak u kojemu se iznosi popis plemićkih obitelji koje su postojale u Bosanskom Kraljevstvu u doba njegove propasti". ${ }^{3}$ U uvodnoj bilješki tumače se okolnosti nastanka Popisa. Vladmirović kaže da se njegov izvornik nalazi u samostanu Svetoga Duha u Fojnici, a da ga je godine 1724. prepisao tadašnji tajnik provincije Bosne Srebrene, fra Marijan Lekušić (1685.-1742.) koji ga je potom pohranio u franjevačkom samostanu Svete Marije u Makarskoj gdje se i danas čuva. Taj prijepis uvezan je kao jedan od dodataka rukopisu makarskog ljetopisca fra Nikole Gojaka (1680.-1772.). ${ }^{4}$ Očito, Kačić je koristio ovaj Lekušićev prijepis pa su se preko njegova popularnog Razgovora podatci o podrijetlu bosanske vlastele proširili među franjevcima i pukom. Vladmirović je Popisu tendenciozno dodao nekoliko rodova iz Dalmatinske zagore i Hercegovine (Domazetović, Dragičević, Matić, Milatović, Radosaljić, Radivojević, Vukšić itd.) kojih nema u Lekušićevu dokumentu. Osim dodavanja novih "plemića", u ovim i kasnijim prijepisima Popisa nastale su stanovite razlike u redoslijedu, imenima rodova i nazivima mjesta njihova podrijetla. Neka dvojna prezimena u različitim verzijama Popisa razdvojena su, a mnoga su u prijepisu iskrivljena ili su krivo zapisana već u Lekušićevu rukopisu po čemu se vidi da je taj dokument nastao "iz treće ruke". Od Kačića i Vladmirovića Popis je preuzeo i makarski svećenik don Petar Bartulović te ga je uza sitne preinake i dodatak nekoliko primorskih rodova objavio u svojoj knjižici o povijesti Hercegovine iz $1791 .{ }^{5}$

Odakle zapravo potječu podatci iz Popisa? Provenijencija i svrha Popisa postaje nam znatno jasnija kada znamo da je fra Marijan Lekušić izradio i jedan od prerisa Fojničkog grbovnika koji se čuvao u ma-

3 Prudentio Narentino [Luka Vladmirović], De Regno Bosniae, ejusque interitu, narratio historica etc, Venetiis, 1781., str. 48-55 (Appendix I. In qua Catalogus exhibetur Familiarum Nobilium in Bosnensi Regno existentium tempore ipsius destructionis).

4 Josip Ante Soldo (prir.), Makarski ljetopisi 17. i 18. stoljeća, Književni krug, Split, 1993., str. 76. Popis je uvezan u svezak Ljetopisa fra Nikole Gojaka koji se čuva u Arhivu Franjevačkoga samostana u Makarskoj (sign. S - 38 f. 78-80').

5 Pietro Bartulovich, Antico Ducato s. Sabba Chelmo Herzegovina dalle barbare rovine, Venezia, 1796., str. XXXIV-XXXV. 
karskom samostanu, a danas je izgubljen. ${ }^{6}$ Glavni korpus Popisa ili njegova nepoznatog izvornika, ako je uopće postojao, obuhvaća rodove iz Fojničkoga i drugih ilirskih grbovnika. Ovom spoznajom Popis gubi značenje vjerodostojnoga izvora za predosmansko razdoblje, a njegov apokrifni karakter dobiva smisao u kontekstu ranonovovjekovnih koncepcija povezanih s ilirskom heraldikom. Vjerojatno je prvi Popis kreirao sam Lekušić, ekscerptirajući imena rodova iz Fojničkoga i Korjenić-Neorićeva grbovnika te drugih izvora i rodoslovlja povezanih s ilirskom heraldikom. Nekim rodovima, uglavnom poznatim i raširenim patronimicima te onima koji su se prema homonimiji mogli povezati s grbovničkima, dodano je "podrijetlo" prema njihovu trenutačnom obitavalištu. Naime, osim imenâ i grbova, Fojnički grbovnik, kao ni ostali ilirski armorijali, ne sadrži podatke o podrijetlu pojedinih rodova. U svakom slučaju, "izvorni" Popis u Fojničkom samostanu već se polovicom 19. stoljeća smatrao davno izgubljenim pa je Lekušićev makarski prijepis iz 1724. zapravo "najstariji".?

Nakon ovih uvida jasno je da se sam Popis i njegov sadržaj moraju tumačiti u sklopu ilirske heraldike. Budući da je Fojnički grbovnik nastao potkraj sedamdesetih godina 17. stoljeća, ili nešto kasnije, kao preris Korjenić-Neorićeva grbovnika iz godine 1595., potrebno se osvrnuti na genezu toga fenomena. Po uzoru na Korjenić-Neorićev grbovnik, prvu zbirku grbova zemalja, dinastija i plemićkih rodova zamišljenog "cesarstva ilirskog", izrađene su do polovice 19. stoljeća brojne verzije u literaturi poznate kao ilirski grbovnici. Uz original, poznata su još 24 primjerka različitih redakcija. U literaturi su se uvriježila i pogrješna tumačenja po kojima se Korjenić-Neorićev grbovnik smatra kopijom još starijeg "virtualnog" protografa Petra Ohmućevića. Zbog toga se često naziva i Ohmućevićevim, a ponekad ga se poistovjećuje sa znatno mlađim ali "poznatijim" Fojničkim grbovnikom. Sadržajno vezani uz original, svi ilirski grbovnici izra-

6 Drugi preris spominje se 1748. u vlasništvu Makaranina don Klementa Grubišića ali se i njemu izgubio trag. O dva prijepisa Fojničkoga grbovnika u Makarskoj, vidi: SRĐAN Rudić, Vlastela ilirskog grbovnika, Istorijski institut, Beograd, 2006., str. 78-79; Frano Glavina, Makarske teme, Gradska galerija Antuna Gojaka, Makarska, 2010., str. 18-19.

7 Povezanost popisa i grbovnika, uočio je već polovicom 19. stoljeća Ivan Franjo Jukić. Već je on zaključio da je imenoslov, kako ga zove, "mnogo kasnije pisan nego ona knjiga slikovna", te da izvornika više nema u fojničkom samostanu. IVAN Franjo Jukić, "Starine bosanske. Rodoslovje popa Stanislava Rupčića", u: Bosanski prijatelj, 2, Zagreb, 1851., str. 82. 
đivani su, precrtavani, prilagođavani, čuvani i korišteni za slične potrebe, u različitim povijesnim okolnostima, od Napulja i Dubrovnika do Fojnice, Beča, Zagreba i Beograda. Sadržaj im je u osnovi jednak. Svi obuhvaćaju predosmanski korpus grbova zemalja i navodnih bosanskih, srpskih, humskih, primorskih, dalmatinskih, hrvatskih i albanskih, jednom riječi, "ilirskih" dinasta i vlastele neovisno o njihovoj konfesionalnoj pripadnosti, starosti, snazi i značenju. Kanonizirane predajom, ove "zakašnjele" zbirke grbova dugo su odolijevale kritičkoj analizi. ${ }^{8}$

Prema jeziku, osliku, starosti papira i genealogijama tvoraca može se zaključiti da je Korjenić-Neorićev grbovnik izrađen kada je i datiran (1595.) ili oko te godine. Iako su mnogi rodovi koji se u njemu spominju povijesno poznati, većinu grbova, njihove motive, tinkture (boje) i metale veoma rijetko možemo potvrditi u starijim izvorima. Stoga je opravdano pretpostaviti da mnoga znamenja u grbovniku nisu autentična i da predstavljaju rekonstrukcije ili potpuno nove kreacije. Međutim, brojni rodovi i/ili njihovi fiktivni nasljednici od 17. stoljeća koristili su grbove iz ovoga grbovnika i njegovih kopija, neki i na temelju vladarskoga odobrenja. S obzirom na vrijeme nastanka razumljiva je pragmatična svrha i ideološka poruka Korjenić-Neorićeva i kasnijih grbovnika. S jedne strane, njima su se legitimirala i potvrđivala stara plemićka prava i povlastice kršćanskih rodova u kraljevstvima, kneštvima i vojvodstvima nekoć moćne imaginarne Ilirije, posebno u srednjovjekovnoj Bosni i Hercegovini. S druge strane, ti su grbovnici predstavljali heraldičku projekciju križarske ideologije koja je u kasnom 16. stoljeću, u duhu katoličke obnove, a pod okriljem španjolske krune i papinstva, prodirala na područje "Ilirika". Svakako, prije nego što je postao historiografskom temom, programski i ideološki sadržaj ilirske heraldike više od dvjesto godina bio je usko povezan s protuosmanskom politikom i reafirmacijom domaće elite.

Začetnici ideje i tvorci prvih grbovnika bili su potomci vlasteličićkih rodova iz neposrednoga dubrovačkog zaleđa, iz Huma i Trebinjske oblasti, koji su pred Osmanlijama prebjegli u Slansko primorje pod okrilje Dubrovačke Republike. Riječ je o pomorskim rodovima: Kor-

8 O kompleksnom problemu nastanka Korjenić-Neorićeva i Fojničkog grbovni$k a$, o ilirskoj heraldici, njezinoj ideologiji i učincima te o literaturi u vezi s tom temom u ovom se članku piše na temelju zaključaka studije: STJEPAN Ćosić, Ideologija rodoslovlja. Korjenić-Neorićev grbovnik iz 1595., HAZU, Zavod za povijesne znanosti u Dubrovniku, Zagreb - Dubrovnik, 2015. 
jenić-Neorićima, odnosno njihovim ograncima Jerinićima i Kmetovićima, Grgurić-Ivelja-Ohmućevićima, Dolisti-Tasovčić-Diničićima, Medvjedović-Orsinijima i o još nekima iz njihova kruga. Brojni pripadnici tih rodova od polovice 16 . i tijekom 17. stoljeća istaknuli su se kao kapetani i zapovjednici u pomorskim pothvatima španjolskih kraljeva Filipa II., III. i IV. ali i kao franjevci, svećenici i biskupi. U političkoj perspektivi zapadnih protuosmanskih koalicija pripadnici slanskih rodova vidjeli su priliku da se nakon reconquiste etabliraju kao nova elita na širem području Ilirika. Stoga je sadržaj grbovnika kreiran upravo po mjeri njihovih gentilnih odnosa i pozivanja na nekadašnje posjede u Bosanskome kraljevstvu. Poznata znamenja zemalja, dinastija i srednjovjekovnih vladarskih rodova "cesarstva Ilirskoga" u grbovnicima bila su pokriće, odnosno aristokratska legitimacija za ove manje poznate ali rodbinski povezane ranonovovjekovne rodove. Mistifikacija o njihovu srednjovjekovnom plemićkom podrijetlu produbila se sa širenjem različitih redakcija i precrta Korjenić-Neorićeva grbovnika.

Uz poznate dinastičke i velikaške rodove i skupinu povezanih rodova koja je bila važna za njegov nastanak, u Korjenić-Neorićevu grbovniku nalazi se i velik broj u izvorima slabo poznatih ili potpuno nepoznatih rodova i njihovih grbova. Za mnoge od njih ne može se pouzdano tvrditi da su imali plemićki status, pa ni to da su uopće postojali. Toj skupini pripada tridesetak rodova. Ostali, manje poznati, otkrivaju nam svoj identitet ako pažnju usmjerimo na područje Hercegovine, neposredno dubrovačko zaleđe (Primorje, Popovo s Trebinjem i Zažablje) te ako u obzir uzmemo podatke iz genealogija Ohmućevića i Korjenić-Neorića. Ta su rodoslovlja važan izvor za tumačenje nastanka i sadržaja grbovnika. Ona nam potvrđuju da je grbovnička "moda" nastala oko jezgre primorskih rodova i bratstava koji su bili u stvarnom ili imaginarnom srodstvu i koji su svoje plemićko podrijetlo vezivali za bosansko-humsku političku tradiciju. Gotovo svi rodovi spomenuti u rodoslovljima tvoraca grbovnika pojavljuju se i u samom grbovniku. Čak 40 rodova iz rodoslovlja Korjenić-Neorića nalazimo i u njihovu grbovniku. Među tim rodovima 11 ih je i u genealogiji Ohmućevića koja pak sadrži još šest rodova kojih nema u Korjenić-Neorićevu rodoslovlju ali čiji su grbovi također u grbovniku. Dakle, u Korjenić-Neorićevu grbovniku zastupljeno je ukupno 46 rodova iz oba rodoslovlja.

Sudeći prema brojnim prerisima grbovnikâ, ilirska je heraldika tijekom 17. i 18. stoljeća doživjela značajnu recepciju, a grbovnički sadr- 
žaji imali su odjeka u europskoj heraldici i genealogiji. Godine 1725. napuljski je plemić Giuseppe Lumaga objavio svojevrsni leksikon europskoga plemstva pod naslovom Teatro della nobiltà dell' Europa etc. u kojemu je uz popise plemićkih rodova u europskim državama i regijama, kao posljednji, donio i popis vlastele "Della Grecia over Schiavonia, e sue Provincie...". Riječ je o doslovnom prijepisu kazala vlastele iz Korjenić-Neorićeva grbovnika (uz odvajanja nekih dvojnih prezimena), bez podataka o podrijetlu ali s posve proizvoljnim talijanskim inačicama prezimena. Zanimljivo je da Lumaga, u napomeni koja prethodi popisu, kao svoj izvor ne spominje grbovnik nego se poziva na autoritet glasovitoga heraldičara Ménestriera i drugih autora. ${ }^{9} \mathrm{Na}$ taj su način "ilirska vlastela" stjecala europsku legitimaciju. S druge strane, Lekušićev, Kačićev i kasniji prijepisi Popisa, u kojima se navodi i podrijetlo većega broja rodova, izrađeni su za lokalnu uporabu kako bi se, uz pomoć homonimije i predaje o podrijetlu i zavičaju pojedinih rodova, uspostavila njihova povijesna veza s predosmanskim Bosanskim kraljevstvom.

Za nastanak Popisa i širenje ilirske heraldike tijekom 18. stoljeća ključna je bila druga poznata inačica ilirskoga grbovnika iz franjevačkoga samostana u Fojnici. Fojnički grbovnik nastao je u posljednjoj četvrtini 17. stoljeća, u vrijeme kada je pripadnik najmlađega ogranka dubrovačkih Ohmućevića, Pijer Damjan, sa sinom Antunom Damjanom, dokazivao svoje pravo na nasljeđe u Slanom ali i na stare posjede svoga roda u Bosni. Odgovor na pitanje kako je došlo do toga da je grbovnik slanskih Ohmućevića dospio u fojnički samostan zacijelo se krije u stoljetnim vezama slanskih franjevaca, od kojih su neki pripadali rodovima Ohmućevića i Korjenić-NeorićKmetovića, s Bosanskom vikarijom i provincijom ali i u činjenici da se Antun Damjan Ohmućević tijekom Velikoga rata istaknuo u borbama u Bosni te da je u to doba obilazio fiktivne posjede svoga roda i

9 [Giuseppe Lumaga], Teatro della nobiltà dell' Europa ovvero Notizia delle Famiglie Nobili, che in Europa vivono di presente, e che in lei vissero prima, Giovan-Francesco Paci, Napoli, 1725., str. 381-387. Lumaga odvaja dvojna prezimena (Dobrašinović-Bogašinović i Vojković-Palikuća) te dvaput navodi Ćihoriće pa njegov popis, za razliku od Korjenić-Neorićeva grbovnika sa 141, broji 144 roda. Vjerojatno Lumaga nije posve lagao kada je naveo da je popis vlastele preuzeo od drugih autora ali u dostupnim tekstovima francuskoga isusovca, heraldičara i antikvara Claude-Françoisa Ménestriera (1631.-1735.), na kojega se poziva, nema traga spominjanju ilirske vlastele, kao ni samoga grbovnika. 
bio u kontaktu s domaćim franjevcima. ${ }^{10}$ Tako su franjevci provincije Bosne Srebrene postali glavni prenositelji grbovničkih sadržaja koji su se miješali s narodnom usmenom tradicijom i "epskom dominantom" u književnosti.

Od kraja 17. stoljeća utilitarnu matricu prvih grbovnika počeli su koristiti brojni pojedinci i rodovi iz različitih područja Ilirije, koji su u protjerivanju Osmanlija vidjeli priliku da se domognu svojih "starih" posjeda i titula. Fenomen "prisvajanja" grbovničkoga znamenja, najčešće na temelju konstruirane predaje i homonimije, osobito se razgranao u Dalmaciji pod mletačkom vlašću pa je obnovljeno i novo plemstvo nicalo diljem "nove" i "najnovije stečevine". Nakon Morejskoga rata (1684.-1699.) i širenja granica te protomodernizacijskih zahvata mletačke vlasti u agrarnoj politici i upravi, heterogena je skupina "knezova", "vojvoda" i "harambaša", uza staro komunalno plemstvo, kao nova elita postala glavni oslonac države. Od godine 1661. mletačka institucija Magistrata nad feudima legalizirala je uporabu plemićkih naslova te otada možemo pratiti priznavanje titula "starom" i dodjeljivanje "novom" dalmatinskom plemstvu. ${ }^{11} \mathrm{U}$ prikupljanju dokumentacije kojom se dokazivala "bolja prošlost" nastale su brojne krivotvorine i obiteljske mistifikacije inspirirane sadržajem grbovnika. ${ }^{12}$ Gradivo koje je omogućilo razvoj tog fenomena najčešće

10 Vidi opširnije: S. Ćosıć, Ideologija rodoslovlja. Korjenić-Neorićev grbovnik iz 1595, str. 154-157.

11 O tom procesu vidi u: Miroslav Granić, "Dalmatinske obitelji u 'Libro aureo dei veri titolati' mletačkog Magistrata nad feudima", u: Radovi Filozofskoga fakulteta u Zadru, 30/17, Zadar, 1990./1991., str. 159-208.

12 Nakon što su u Veneciji isposlovali plemićki status za svoje rodove, trend genealoških mistifikacija što su ga potaknuli fra Andrija Kačić Miošić, a osobito fra Luka Vladmirović, proširio se Dalmacijom. Vidi: JosıP AnTE Soldo, "Luka Vladmirović i njegov krug", u: Historijski zbornik, 36, Zagreb, 1983., str. 189-213. Tijekom druge polovice 18. stoljeća objavljen je čitav niz djela u kojima se "dokazuje" najčešće bosansko-humsko plemićko podrijetlo pojedinih rodova Makarskoga primorja. Tako Ivan Josip Pavlović Lučić, u preradbi Mrnavićevoga životopisa Svetoga Save, makarske Batošiće izravno povezuje s Nemanjićima, a Petar Bartulović u svojim knjižicama piše o starom plemstvu brojnih makarskih i primorskih rodova, napose o svojim Bartulovićima te o drveničkim Kostanićima, kozičkim Ravlićima, makarskim Ipšićima, velobrdskim Nemčićima i drugima. Vidi: Ivan Josip Pavlović Lučić, Vita S. Sabbae Abbatis etc., Sebastian Coleti, Venetiis, 1789. te djela Petra Bartulovića: Epitome del privilegio e rolo di Macarsca, Primorie, e Craina etc., Simon Cordella, Venezia, 1794.; Dalmazia antica e recente colle sue gloriose militari virtù, Francesco Andreola, Venezia, 1795.; Antico duca- 
je dolazilo iz franjevačkih krugova. Franjevački samostani u Makarskom primorju i zaleđu bili su sve do 1735. godine u sklopu Bosanske provincije, a početkom 18. stoljeća među pukom je još živjela predaja o hercegu Stjepanu i predturskim vremenima. Sjećanje na tri uzastopna rata s Osmanlijama također je bilo svježe, a privilegirani status u mletačkim okvirima poticao je starosjedilačke ambicije.

Kao starinar i zaljubljenik u domovinsku prošlost Lekušić je, bez paleografskoga znanje i kritičkoga odnosa prema gradivu, započeo prikupljati i prepisivati stare dokumente i isprave smatrajući da je Fojnički grbovnik autentični srednjovjekovni izvor. U tom smislu Popis predstavlja stanovitu dopunu grbovnika, pokušaj da se na temelju homonimije i suvremenih okolnosti, prikaže "raspored" i utvrdi podrijetlo "starih" plemićkih rodova. Uz podatke o podrijetlu dinastičkih rodova, poznate iz usmene predaje, u Popisu su zapravo zabilježena "ognjišta" niza Lekušiću poznatih bosanskohercegovačkih i dalmatinskih rodova. ${ }^{13}$

S obzirom da je navodni izvornik u fojničkom samostanu bio izgubljen, ili kao predložak nije ni postojao, intervencija je načinjena i u samome grbovniku. Naime, potkraj 19. stoljeća netko je na početku Fojničkoga grbovnika uvezao kazalo: 3 lista papira, s abecednim popisom grbova i rodova te pripadajućim brojem stranice. Znatno kasnije, drugom rukom, uz neke je rodove u tom kazalu dodano i podrijetlo identično onome u Lekušićevu, odnosno Kačićevu Popisu. Pripisima je na dnu prve stranice kazala dodana bilješka koja to potvrđuje: "Ove

to S. Sabba Chelmo Herzegovina dalle barbare rovine, Venezia, 1796.; Nobil antica Rauliich da Coziza Gorska xupa Vargoraz, Venezia, 1796.; Chronicon della Dedizione e Privilegio di Macarsca, Primorie, e Craina in ugualità de Pastrovichio dalla Maestà Veneta, conceduto, e confermato, Francesco Andreola, Venezia, 1797.

13 U Popisu i u ilirskim grbovnicima mnoštvo je patronimskih prezimena, a mnoga od njih imaju više varijanti i homonimijski su prilagodljiva. Zavičaj rodova s tim prezimenima bio je poznat franjevcima pa su tako i nastali podatci u Popisu. Neki rodovi, ili njihovi pripadnici, bili su poznati u tim krajevima, a neki su na tim područjima i danas. Tako se npr. u Popisu navode sljedeći rodovi: Aljinić od Bobovca, Aračinović od Broćna, Brzojević iz Rogoznice između Omiša i Zadvarja, Bilošijević iz Raškog kod Mostara, Bibić od Midenog Brda iz Zagorja, Čubretić knezovi od Vrlike, Kopčić od Žrnovnice u Rami, Kosović knezovi od Cetine, Kružić bani, duke i markizi od Klisa, Mirilović iz Petrova polja, Rajković iz Ogorja, itd, itd. Stanovite pogrješke, to jest prilagodbe, u Popisima su zajedničke, poput pretvaranja starog humskog roda Čihorić u Čorić i njegova smještanja u Tuzlu. 
nastavke mjestâ povadio sam iz jednoga kataloga manastira u Makarskoj, koji je 1724. ovdale iz Fojnice popisan ali ga ovde sada nejma. P. V." Prema inicijalima, autor tog dodatka vjerojatno je fra Paškal Vešara (1906.-1979.) koji se tijekom prošloga stoljeća bavio grbovnikom priređujući i njegovo prvo tiskano izdanje iz 1972. godine.

Autentičnost Popisa od njegove se pojave nije dovodila u pitanje pa je taj "dokument", osim simbolične vrijednosti za rodove koji su se na njega pozivali, preko više tiskanih verzija zadobio stanovito historiografsko značenje. Štoviše, s vremenom je uvršten u respektabilne zbirke izvora. Za to je, međutim, bio zaslužan kontinentalni pravac njegova širenja u granicama Provincije Bosne Srebrene. Franjevačkim je vezama, preko povjesničara i arhivista fra Josipa Jakošića (1734.1804.) drugi prijepis Popisa dospio u knjižnicu budimskih franjevaca. Priređujući 1789. rukopise slovačkoga Hrvata i svoga sumještanina Gabrijela Kolinovića Šenkvičkog (1698.-1770.), Jakošićevu je verziju Popisa uočio arhivist Martin Juraj Kovačić (1743.-1821.) i objavio je kao dodatak Kolinovićevoj knjizi Chronicon militaris ordinis equitum templariorum. ${ }^{14}$ Ovaj budimski Popis pod naslovom Nomina nobilium regni Bosnae familiarum sadrži 172 roda i neznatno se razlikuje od Lekušićeva to jest Kačićeva i Vladmirovićeva s tim da su prezimena prepisana uz mnogo više pogrješaka. Prepisivač je Popis obogatio "panonskim" ogrankom bosanske plemićke dijaspore. U autorovu je čast dodan rod "Colonovich", uvršteni su još i daruvarski Jankovići, a nepoznati Pašačići pragmatično su pročitani kao požeški Patačići.

$\mathrm{Na}$ temelju Kovačićeve redakcije, u razdoblju poznanstvenjenja historiografije, uslijedile su još dvije identične edicije Popisa. Baveći se rukopisima i knjigama budimske knjižnice, Popis je pod istim naslovom (Nomina nobilium regni Bosnae familiarum) prvo objavio fra Grgur Čevapović (1786.-1830.) u svojoj povijesti Provincije Sv. Ivana Kapistranskog iz $1823 .{ }^{15}$ Najzad isti Popis je tiskao i fra Euzebije Fermendžin 1892. kao zadnji dokument u glasovitoj zbirci izvora Acta

14 Gabrielis Kolinovics Senquiczensis, Cronicon militaris ordinis equitum etc., Pestini, s. a. [1789.], str. 131-138 (Appendix). O djelovanju priređivača knjige, slovačkoga Hrvata i učenjaka Martina Jurja i njegova sina Josipa Nikole Kovačića kao prvih službenih skupljača arhivskoga gradiva za budimski arhiv, vidi: Ivica Filıpović, "Martin Juraj i Josip Nikola Kovačić u Hrvatskoj 1812-1815.", u: Arhivski vjesnik, 9, Zagreb, 1966., str. 273-284.

15 [Grgur Čevapović], Synoptico-Memorialis Catalogus Observantis minorum provinciae S. Ioannis Capistrano olim Bosnae Argentinae etc., Typis Regiae universitatis hungaricae, Budae, 1823., str. 265-269. 
Bosnae. ${ }^{16}$ Fermendžin se izrijekom poziva na Kovačićev dodatak u Kolinovićevoj knjizi, tumači da je riječ o prijepisu koji je u Fojničkome samostanu izradio fra Josip Jakošić te navodi i njegovu signaturu u knjižnici samostana Male braće u Budimu. Čevapovićeva i Fermendžinova djela postala su standardna istraživačka pomagala pa je, unatoč objašnjenju koje je Fermendžin iznio u pratećoj bilješki, Popis stekao auru autentičnosti te se kao pouzdan izvor često koristio, a i danas se koristi u akademskoj literaturi i publicistici. Pod autoritetom uglednih edicija proizvoljni podatci iz Nomina nobilium regni Bosnae familiarum tako su dospjeli u tekstove o ilirskim grbovnicima, njihovim rodovima i srednjovjekovnoj Bosni i Humu.

Zbog brojnih pogrješaka i konstruiranih atribucija apokrifni Popis već dva stoljeća unosi golemu zbrku u proučavanje grbovnika i genealogija rodova koji se u njima spominju. Evo najvažnijega primjera: Vrhunac zabune u tumačenju podrijetla grbovničkih rodova nastao je nakon što je Aleksandar Solovjev u svome radu o ilirskoj heraldici iz 1933. godine objavio "Plan i poreklo zbornika Korenića-Neorića".17 U pokušaju odgonetanja provenijencije brojnih nepoznatih rodova, Solovjev, uz druge izvore, u "Planu" redovito navodi i podrijetlo rodova koje je iz Popisa u svoju pjesmaricu uvrstio fra Andrija Kačić Miošić. Te podatke iz Kačićeva Popisa Solovjev je u "Planu" označio slovom "K". Sve do 1991. godine Korjenić-Neorićev grbovnik nije bio reproduciran pa je bio teško dostupan za istraživanje, a rad Solovjeva smatrao se najvažnijom studijom o tom grbovniku. Stoga su mnogi koji su o njemu pisali podatke o podrijetlu rodova s oznakom "K" prihvaćali kao vjerodostojne, a neki su i čitav Solovjevljev "Plan" smatrali integralnim dijelom grbovnika. Na Kačićeve (to jest Lekušićeve) i druge podatke iz Popisa, s više ili manje pouzdanja pozivali su se svi istraživači ilirske heraldike iako u samom Korjenić-Neorićevu i u drugim grbovnicima nema niti slova o podrijetlu i povijesti rodova i njihovih grbova.

16 Eusebius FermendžIn (collegit ed digessit), Acta Bosnae potissimum ecclesiastica cum insertis editorum documentorum regestis ab anno 925 usque ad annum 1752, Academia scientiarium et artium slavorum meridionalium, Zagrabiae, 1892., str. 559-562. Signatura budimskoga prijepisa je: Cod. msc. adversar. libr. VIII. num. 21.

17 Aleksandar Solovjev, "Postanak ilirske heraldike i porodica Ohmućević", u: Glasnik Skopskog učenog društva, 12, Skopje, 1933., str. 96-99. 


\section{Apocryphal List of Nobility Kindreds in the Bosnian Kingdom}

\section{Summary}

For more than two centuries, there have been very similar versions of the lists of noblemen of Bosnia and Hum from the pre-Ottoman period in historiography and publishing. One version was published in two well-known collections of sources for the history of $\mathrm{BiH}$, which gave scientific credentials to the list. However, the data on the origin of the list do not confirm their authenticity. The list is one of the apocryphal documents that emerged within the so called Illyrian heraldry. It is a complex ideological phenomenon developed in the course of the anti-Ottoman politics of the $17^{\text {th }}$ and $18^{\text {th }}$ century with the aim of legitimizing the feudal interests of certain kinship circles, as well as the "return" of their privileges and possessions, primarily on the territory of $\mathrm{BiH}$. Some families of the Makarska coast called upon this tradition, and in the Franciscan monastery of Makarska there is the oldest transcript of the list, which, according to some sources, was brought by Fr. Marijan Lekusic from Fojnica in 1724. The list consists of a somewhat modified and expanded sequence of kind reds from the Fojnica Armorial, which was compiled after 1675 . A significant number of kindreds in the list have been added to their place of origin based on the knowledge about their homeland at the beginning of the $18^{\text {th }}$ century. After the Makarska version of the list published by Fr. Andrija Kacic Miosic and Fr. Luka Vladmirovic, a very similar list was presented by Fr. Josip Jakosic who brought it from Bosnia to the Franciscan monastery in Buda. In 1789 Martin Juraj Kovacic printed this list as an addition to the book by Gabrijel Kolinovic. According to the Buda version, Grgur Cevapovic and Euzebije Fermendzin later published the list in their collections of sources. The widespread and uncritical acceptance of apocryphal data from the list and other sources of Illyrian heraldry caused numerous errors and misunderstandings in genealogy and heraldic research.

Keywords: the list of the Bosnia and Hum nobility; Marijan Lekusic; Andrija Kacic Miosic; Luka Vladmirovic; Makarska; Fojnica; Buda; Illyrian heraldry; the Fojnica Armorial; Korjenic-Neoric armorial; Gabrijel Kolinovic Senkvicki; Josip Jakosic; Martin Juraj Kovacic; Grgur Cevapovic; Euzebije Fermendzin. 